\title{
Crescimento da população de cidades do sul e sudoeste de Minas Gerais para determinar área de aterros sanitários
}

\author{
Population growth in cities in the south and southwest of Minas Gerais to determine landfill area \\ Crecimiento de la población en ciudades del sur y suroeste de Minas Gerais para determinar el \\ área del vertedero
}

Recebido: 24/08/2021 | Revisado: 29/08/2021 | Aceito: 01/09/2021 | Publicado: 05/09/2021

Lucas Menezes Felizardo

ORCID: https://orcid.org/0000-0002-9676-0623 Universidade Estadual Paulista “Júlio de Mesquita Filho", Brasil

E-mail: lucas.felizardo@unesp.br

Mauricio Santini Junior

ORCID: https://orcid.org/ 0000-0002-7208-1108 Universidade Estadual Paulista "Júlio de Mesquita Filho", Brasil E-mail: santini.mauricio@ifsp.edu.br

Glaucia Amorim Faria

ORCID: https://orcid.org/0000-0003-2474-4840 Universidade Estadual Paulista "Júlio de Mesquita Filho", Brasil

E-mail:glaucia.a.faria@unesp.br

Katia Luciene Maltoni

ORCID: https://orcid.org/ 0000-0001-6619-4504 Universidade Estadual Paulista "Júlio de Mesquita Filho", Brasil

E-mail: katia.maltoni@unesp.br

Jefferson Nascimento de Oliveira

ORCID: https://orcid.org/ 0000-0002-4453-6347 Universidade Estadual Paulista "Júlio de Mesquita Filho", Brasil E-mail: jefferson.nascimento@unesp.br

Diego Javier Pérez Ortega

ORCID: https://orcid.org/0000-0003-3591-5166

Universidad Cooperativa de Colombia, Colômbia E-mail: diegojavierperez77@ hotmail.com

Gilberto Coelho

ORCID: https://orcid org/0000-0002-0654-2754 Universidade Federal de Lavras, Brasil E-mail: coelho@ufla.br

\begin{abstract}
Resumo
O conhecimento da área mínima de um aterro é um dos passos iniciais para sua implementação, o uso das estimativas de crescimento populacional e econômico vem se mostrando bem eficaz na determinação da área mínima do aterro. Este trabalho teve como objetivo determinar a área mínima de aterros sanitários usando a estimativa de crescimento da população, bem como o atual desenvolvimento econômico do país. Para compor esse estudo os municípios foram divididos em microrregiões estabelecidas por meio de proximidade e foram escolhidos de forma aleatória 2 ou 3 municípios de cada uma das microrregiões. Foi calculada a população final de cada um dos municípios ao fim da vida útil dos aterros e estimada a população após 25 anos para conhecer o volume de lixo em 2045. Os resultados encontrados neste trabalho confirmam a teoria de que quanto maior, mais desenvolvida e mais rica a população, mais resíduo sólido é gerado, pois a diversidade encontrada nos tamanhos dos aterros foi diretamente relacionada ao tamanho da população e ao desenvolvimento. A menor área de aterro estimada $10.600 \mathrm{~m}^{2}$ foi em Fama e a maior $688.560 \mathrm{~m}^{2}$ na cidade de Poços de Caldas.
\end{abstract}

Palavras-chave: Consórcios intermunicipais; Estimação de crescimento; Gestão de Resíduos Sólidos Urbanos (RSU).

\begin{abstract}
The knowledge of the minimum area of a landfill is one of the initial steps for its implementation, the use of estimates of population and economic growth has been shown to be very effective in determining the minimum area of the landfill. This work aimed to determine the minimum landfill area using the population growth estimate, as well as the use of the country's current economic development. To compose this study, the municipalities were divided into micro-regions established through proximity and 2 or 3 municipalities from each of the micro-regions were chosen at random. The final population of each municipality was calculated at the end of the landfill's useful life and the population after 25 years was estimated to know the volume of garbage in 2045. The results found in this work
\end{abstract}


confirm the theory that the larger, more developed and more the population is rich, more solid waste is generated, as the diversity found in landfill sizes was directly related to population size and development. The smallest landfill area estimated at 10,600 $\mathrm{m}^{2}$ was in Fama and the largest 688,560 $\mathrm{m}^{2}$ in the city of Poços de Caldas.

Keywords: Inter-Consortia; Estimation of growth; Urban Solid Waste Management.

\section{Resumen}

El conocimiento del área mínima de un relleno sanitario es uno de los pasos iniciales para su implementación, el uso de estimaciones de población y crecimiento económico ha demostrado ser muy efectivo para determinar el área mínima del relleno sanitario. Este trabajo tuvo como objetivo determinar el área mínima de relleno utilizando la estimación de crecimiento poblacional, así como el uso del desarrollo económico actual del país. Para componer este estudio, los municipios se dividieron en microrregiones establecidas por proximidad y se eligieron al azar 2 o 3 municipios de cada una de las microrregiones. La población final de cada municipio se calculó al final de la vida útil del relleno sanitario y se estimó la población a los 25 años para conocer el volumen de basura en 2045. Los resultados encontrados en este trabajo confirman la teoría de que cuanto más grande, más desarrollado y más la población es rica, se generan más desechos sólidos, ya que la diversidad encontrada en los tamaños de los rellenos sanitarios estaba directamente relacionada con el tamaño y el desarrollo de la población. El relleno sanitario más pequeño estimado en $10.600 \mathrm{~m}^{2}$ se encuentra en Fama y el más grande $688.560 \mathrm{~m}^{2}$ en la ciudad de Poços de Caldas.

Palabras clave: Inter consorcios; Estimación de crecimiento; Gestión de Residuos Sólidos Urbanos.

\section{Introdução}

A urbanização ocorrida devido ao crescimento das cidades e ao aumento do consumo, vem contribuindo para um significativo aumento na produção de resíduos sólidos urbanos - RSU, gerando um problema de extrema relevância na atualidade. Ao longo do século XX o Brasil passou por intenso e acelerado processo de urbanização (SANTOS, 2020), as cidades cresceram e, na maioria dos casos, se desenvolveram sem planejamento, acarretando diversos problemas, oriundos da falta de políticas públicas, como na área de saneamento básico.

Nos últimos três anos os incrementos na produção de RSU se mantiveram constantes e em torno de $1,03 \%$. No entanto, nos anos anteriores essa produção cresceu em ritmo mais acelerado do que o crescimento da população urbana, como apresentado em 2017 no Panorama dos Resíduos Sólidos no Brasil (ABRELPE, 2017), o qual relata uma produção de 79 milhões de toneladas de RSU em 2018, com crescimento um pouco menor que $1 \%$ em relação a 2017. Percebe-se então que o aumento da população segue associado a maior geração de lixo por habitante, chamando a atenção para o volume de RSU que ainda pode ser produzido.

Em 2010, foi sancionada a Lei $\mathrm{n}^{\circ}$ 12.305, que trata da política nacional de resíduos, nesta ficou determinado que as administrações públicas municipais, independente de seu porte e localização, devem construir aterros sanitários ou industriais, encerrando as atividades de lixões e aterros controlados, no prazo máximo de 4 (quatro) anos, nesses aterros só poderão ser depositados resíduos sem qualquer possibilidade de reciclagem e reaproveitamento, determinando também que se proceda à compostagem dos resíduos orgânicos. Determinou também o prazo máximo de 2 (dois) anos, ou seja, até o fim do ano de 2012 para apresentação do Plano de Gestão Integrada de Resíduos.

Os municípios não cumpridores destes compromissos estariam proibidos de receber recursos de fontes federais, destinadas ao gerenciamento de resíduos, inclusive empréstimos (Caixa Econômica Federal -CEF e Banco Nacional de Desenvolvimento -BNDES). Infelizmente este prazo vem sendo prorrogado sem a aplicação das sanções previstas na lei.

O aterro sanitário foi a forma encontrada para disposição dos RSU no solo, com a proposição de minimizar problemas relacionados à saúde pública e ao meio ambiente. Utiliza técnicas de compactação para confinar os RSU numa menor área e volume, além de recobri-lo com uma camada de terra ao final de cada trabalho, ou em intervalos ainda menores (Silva \& Zaidan, 2004; FEMA, 2010), como consta da NBR 8419/1984, da ABNT (Associação Brasil de Normas Técnicas).

Para atender aos requisitos já citados a adequada localização do aterro sanitário é muito importante, e deve contemplar pontos como potencial de contaminação do lençol freático, permeabilidade do solo, proximidade de cursos d'água, 
acessibilidade, população, impacto no paisagismo, proteção de habitats naturais, potencial agrícola da região, proximidade de núcleos residenciais, de aeroportos e a interação com a dinâmica da comunidade local (Norese (2006); Lima (2005).

Para auxiliar na seleção do local adequado ao aterro sanitário, Guevara et al. (2017) utilizou o SIG como ferramenta de análise, combinada com critérios técnicos, ambientais e econômicos.

Nos últimos anos observa-se melhora significativa nos cuidados com o tratamento e a destinação final dos RSU no Brasil. Como consequência dessa evolução, nota-se redução na quantidade de resíduos acumulados em lixões e aumento da quantidade disposta em aterros controlados e sanitários, além de se verificar pequeno crescimento na separação de materiais constituintes dos RSU, visando à reciclagem e compostagem. (Prado Filho \& Sobreira, 2007).

Além da localização o tamanho mínimo do aterro sanitário também precisa ser definido, para que esteja adequado ao local escolhido. Assim, é necessário usar parâmetros populacionais, dentre estes tem-se população atual, taxa anual de crescimento, tempo de utilização do aterro (em anos), quantidade de lixo diária, volume de resíduo produzido, volume final de resíduo e altura máxima recomendada para o aterro. (Santos, 2019)

Para esta definição é necessário utilizar estimadores estatísticos, cuja função é estimar parâmetros e, os valores assim obtidos, são chamados de estimativas, as quais podem contribuir para a determinação do tamanho mínimo do aterro, tomando por base a estimativa da população do município e considerando o ritmo atual de desenvolvimento da economia brasileira.

Diante das considerações apresentadas, utiliza-se, neste trabalho, uma metodologia estatística para estimar a área mínima de aterros sanitários de alguns municípios do sul e sudoeste de Minas Gerais, para uso por um período de 25 anos.

\section{Metodologia}

Os municípios que compõem esse estudo foram divididos em 12 microrregiões, 10 delas podem ser vistos na Figura 1 e foram acrescidas as microrregiões de Campo Belo e Lavras, que embora façam parte do sul de Minas não foram apresentadas na figura.

Figura 1 - Divisão das 10 microrregiões localizadas no sul e sudoeste de Minas Gerais.

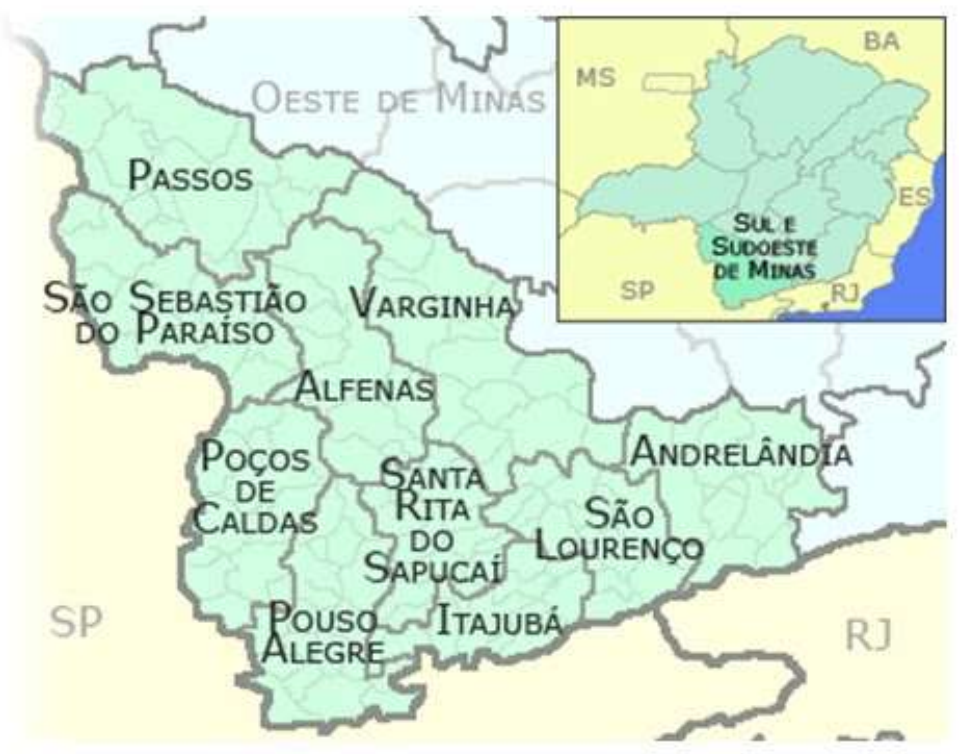

Fonte: Adaptado Google Imagens.

Deste modo foram avaliadas 12 microrregiões: 
1- Microrregião Alfenas: compreende 12 municípios, Alfenas, Alterosa, Areado, Carmo do Rio Claro, Carvalhópolis, Conceição da Aparecida, Divisa Nova, Fama, Machado, Paraguaçu, Poço Fundo e Serrania.

2- Microrregião Andrelândia: compreende 13 municípios, Aiuruoca, Andrelândia, Arantina, Bocaina de Minas, Bom Jardim de Minas, Carvalhos, Cruzília, Liberdade, Minduri, Passa Vinte, São Vicente de Minas, Seritinga e Serranos.

3- Microrregião Campo Belo: com 7 municípios, sendo eles: Aguanil, Campo Belo, Cana Verde, Candeias, Cristais, Perdões, Santana do Jacaré.

4- Microrregião Itajubá: com 13 municípios, Brasópolis, Consolação, Cristina, Delfim Moreira, Dom Viçoso, Itajubá, Maria da Fé, Marmelópolis, Paraisópolis, Piranguçu, Piranguinho, Virgínia, Wenceslau Braz.

5- Microrregião Lavras: com 9 municípios, Carrancas, Ijaci, Ingaí, Itumirim, Itutinga, Lavras, Luminárias, Nepomuceno e Ribeirão Vermelho.

6- Microrregião Passos: com 14 municípios, Alpinópolis, Bom Jesus da Penha, Capetinga, Capitólio, Cássia, Claraval, Delfinópolis, Fortaleza de Minas, Ibiraci, Itaú de Minas, Passos, Pratápolis, São João Batista do Glória, São José da Barra.

7- Microrregião Poços de Caldas: com 13 municípios, Albertina, Andradas, Bandeira do Sul, Botelhos, Caldas, Campestre, Ibitiura de Minas, Inconfidentes, Jacutinga, Monte Sião, Ouro Fino, Poços de Caldas e Santa Rita de Caldas.

8- Microrregião Pouso Alegre: com 20 municípios, Bom Repouso, Borda da Mata, Bueno Brandão, Camanducaia, Cambuí, Congonhal, Córrego do Bom Jesus, Espírito Santo do Dourado, Estiva, Extrema, Gonçalves, Ipuiúna, Itapeva, Munhoz, Pouso Alegre, Sapucaí Mirim, Senador Amaral, Senador José Bento, Tocos do Moji e Toledo.

9- Microrregião Santa Rita do Sapucaí: com 15 municípios, Cachoeira de Minas, Careaçu, Conceição das Pedras, Conceição dos Ouros, Cordislândia, Heliodora, Natércia, Pedralva, Santa Rita do Sapucaí, São Gonçalo do Sapucaí, São João da Mata, São José do Alegre, São Sebastião da Bela Vista, Silvianópolis e Turvolândia.

10- Microrregião São Lourenço: com 16 municípios, Alagoa, Baependi, Cambuquira, Carmo de Minas, Caxambu, Conceição do Rio Verde, Itamonte, Itanhandu, Jesuânia, Lambari, Olímpio Noronha, Passa Quatro, Pouso Alto, São Lourenço, São Sebastião do Rio Verde e Soledade de Minas.

11- Microrregião São Sebastião do Paraíso: com 14 municípios, Arceburgo, Cabo Verde, Guaranésia, Guaxupé, Itamogi, Jacuí, Juruaia, Monte Belo, Monte Santo de Minas, Muzambinho, Nova Resende, São Pedro da União, São Sebastião do Paraíso e São Tomás de Aquino.

12- Microrregião Varginha: com 16 municípios, Boa Esperança, Campanha, Campo do Meio, Campos Gerais, Carmo da Cachoeira, Coqueiral, Elói Mendes, Guapé, Ilicínea, Monsenhor Paulo, Santana da Vargem, São Bento Abade, São Tomé das Letras, Três Corações, Três Pontas e Varginha.

Em cada uma destas microrregiões foram escolhidos de forma aleatória 2 ou 3 municípios, para o cálculo do tamanho mínimo do aterro sanitário, de forma a representar de modo amplo os municípios do sul e sudoeste de Minas gerais.

Para estimar a população de cada um dos municípios ao fim da vida útil dos aterros será utiliza a equação 1.

$$
\text { pop }_{\mathrm{f}}=\mathrm{p}_{0} \cdot(1+\mathrm{d})^{\mathrm{t}}
$$

Em que: $\operatorname{pop}_{\mathrm{f}}=$ população estimada ao final da vida útil do aterro, $\mathrm{p}_{0}=$ a população atual, $\mathrm{d}=$ taxa anual de crescimento e $t=$ tempo em anos.

Assim, em 2045 a população estimada será como indicado abaixo:

$$
\text { pop }_{2045}=\mathrm{p}_{0} \cdot(1+0,0115)^{25}
$$

Para cálculo da população estimada para 2045 utilizaram-se os dados do censo do IBGE 2010 (IBGE, 2010) e com a taxa anual de crescimento observada pelo IBGE para população brasileira de 1,15\%. 
Estimado o tamanho da população, após vinte e cinco anos, estima-se o volume de lixo produzido. De acordo com dados da ABRELPE (Associação Brasileira de Empresas de Limpeza Pública e Resíduos Especiais), em 2016, cada brasileiro gerou em torno de $1,032 \mathrm{~kg}$ de resíduos e, em 2017, esse número praticamente se manteve: 1,035, a quantidade de lixo produzida foi calculada pela equação 3 . Em que $Q_{\mathrm{f}}$ é a quantidade de lixo diário, $\mathrm{kg}$.

$$
\mathrm{Q}_{\mathrm{f}}=\operatorname{pop}_{\mathrm{f}} \cdot 1,03
$$

Para o cálculo relativo ao ano de 2045 foi utilizada a equação 4 .

$$
\mathrm{Q}_{2045}=\text { pop }_{2045} \cdot 1,03
$$

Para calcular o volume diário $\mathrm{V}_{\mathrm{d}}$ de resíduo produzido, utilizou-se a equação 5 .

$$
V_{d}=\frac{Q_{f}}{P_{E}}
$$

Em que $\mathrm{V}_{\mathrm{d}}=$ volume diário de resíduo produzido $\left(\mathrm{m}^{3} \mathrm{dia}^{-1}\right)$ e $\mathrm{P}_{\mathrm{e}}$ é peso específico do resíduo compactado $\left(\mathrm{kg} \mathrm{m}^{-3}\right)$. Segundo HADDAD (1999) o peso dos resíduos sólidos varia entre 500 e $700 \mathrm{~kg} \mathrm{~m}^{-3}$. No pior cenário ficaria conforme a equação 6.

$$
V_{d}=\frac{Q_{2045}}{500}
$$

Assim, estima-se por meio da equação 7 o volume final $\left(\mathrm{V}_{\mathrm{f}}\right)$ de resíduos produzidos ao longo de 25 anos.

$$
V_{f}=V_{d} * 365 \text { dias } * 25 \text { anos }
$$

Estimado o volume final necessário para o aterro, determina-se o tamanho mínimo da área do aterro $\left(\mathrm{A}_{\min }\right)$ com base na população estimada para uma vida útil de 25 anos, pela equação 8 .

$$
\mathrm{A}_{\min }=\frac{\mathrm{V}_{\mathrm{f}}}{\mathrm{h}}
$$

Em que h é a altura máxima recomendada para as valas do aterro sanitário, delimitada em $6 \mathrm{~m}$ por questões técnicas (Lourenço et al, 2015).

No tocante aos valores obtidos, não foi considerado o incremento da camada de solo utilizada ao fim de cada jornada de trabalho o que em alguns estudos tem informado ser cerca de 10\% do volume final (Paula, 2017), podendo aumentar assim a área mínima do aterro.

\section{Resultados e Discussão}

Como rege a Lei $\mathrm{N}^{\circ}$ 12.305/2010 todos os municípios do Brasil deveriam ter um local adequado para a deposição final de seus RSU até o final de 2014. Infelizmente esta data vem sendo prorrogada e ainda hoje não se estabeleceu uma data limite para que a Lei seja cobrada.

Com os resultados obtidos neste trabalho (Tabela 1) é possível fazer indicações sobre a demanda por aterros sanitários em cada município estudado, contribuindo para as tomadas de decisões necessárias para resolver os problemas gerados pelos RSU, permitindo que os municípios se antecipem às exigências da lei $\mathrm{n}^{\circ} 12.305 / 2010$, uma vez que a determinação do tamanho mínimo da área que será ocupada pelo aterro sanitário é fundamental para organização das estratégias de implementação e gestão do mesmo..

Os tamanhos mínimos para aterros sanitários obtidos e expressos na Tabela 1 podem subsidiar tomadas de decisão e a união de municípios, em consórcios, somando suas necessidades de área, para escolha de um local comum para deposição do RSU com possível redução de gastos e impactos ambientais, não perdendo de vista que, além do tamanho, a área deve obedecer a critérios técnicos. 
Tabela 1 - Área mínima dos aterros sanitários (Amin, em $\mathrm{m}^{2}$ ) com base no número de habitantes dos municípios (dados do Censo IBGE 2010). População atual (P0); População em 2045 (Pop2045); Quantidade de RSU em Kg/Dia (Qf); Volume diário de RSU em m $\left(V_{\mathrm{f}}\right)$; Volume Total do Aterro em Anos em m³ (VTA).

\begin{tabular}{|c|c|c|c|c|c|c|}
\hline \multirow{2}{*}{ Cidades } & P0 & Pop2045 & \multirow{2}{*}{$\begin{array}{c}\text { Qf } \\
\text { (kg/dia) }\end{array}$} & \multirow{2}{*}{$\begin{array}{c}\mathbf{V f} \\
\left(\mathbf{m}^{3}\right)\end{array}$} & \multirow{2}{*}{$\begin{array}{l}\text { VTA } \\
\left(\mathbf{m}^{3}\right)\end{array}$} & \multirow{2}{*}{$\begin{array}{c}\text { Amin } \\
\left(\mathrm{m}^{2}\right)\end{array}$} \\
\hline & \multicolumn{2}{|c|}{ (n ${ }^{\circ}$ de habitantes) } & & & & \\
\hline Aiuruoca & 6.162 & 8.884 & 9.151 & 18 & 167.005 & 27.834 \\
\hline Alfenas & 73.774 & 106.368 & 109.559 & 219 & 1.999 .456 & 333.243 \\
\hline Alterosa & 13.717 & 19.777 & 20.371 & 41 & 371.764 & 61.961 \\
\hline Andradas & 37.270 & 53.736 & 55.348 & 111 & 1.010 .108 & 168.351 \\
\hline Bom Sucesso & 17.243 & 24.861 & 25.607 & 51 & 467.327 & 77.888 \\
\hline Campo Belo & 51.544 & 74.317 & 76.546 & 153 & 1.396 .968 & 232.828 \\
\hline Carrancas & 3.948 & 5.692 & 5.863 & 12 & 107.000 & 17.833 \\
\hline Coqueiral & 9.289 & 13.393 & 13.795 & 28 & 251.755 & 41.959 \\
\hline Divisa Nova & 5.763 & 8.309 & 8.558 & 17 & 156.191 & 26.032 \\
\hline Estiva & 10.845 & 15.636 & 16.106 & 32 & 293.926 & 48.988 \\
\hline Fama & 2.350 & 3.388 & 3.490 & 7 & 63.691 & 10.615 \\
\hline Gonçalves & 4.220 & 6.084 & 6.267 & 13 & 114.372 & 19.062 \\
\hline Guaxupe & 49.430 & 71.269 & 73.407 & 147 & 1.339 .674 & 223.279 \\
\hline Heliodora & 6121 & 8.825 & 9.090 & 18 & 165.894 & 27.649 \\
\hline Ibiraci & 12.176 & 17.555 & 18.082 & 36 & 329.999 & 55.000 \\
\hline Ijaci & 5.859 & 8.448 & 8.701 & 17 & 158.793 & 26.466 \\
\hline Itumirim & 6.139 & 8.851 & 9.117 & 18 & 166.382 & 27.730 \\
\hline Lavras & 92.200 & 132.935 & 136.923 & 274 & 2.498 .845 & 416.474 \\
\hline Nepomuceno & 25.733 & 37.102 & 38.215 & 76 & 697.427 & 116.238 \\
\hline Passos & 106.290 & 153.250 & 157.848 & 316 & 2.880 .719 & 480.120 \\
\hline Perdões & 20.087 & 28.962 & 29.831 & 60 & 544.407 & 90.734 \\
\hline Poços de Caldas & 152.435 & 219.782 & 226.376 & 453 & 4.131 .361 & 688.560 \\
\hline Pouso Alegre & 130.615 & 188.322 & 193.972 & 388 & 3.539 .986 & 589.998 \\
\hline Ribeirão Vermelho & 3.826 & 5.516 & 5.682 & 11 & 103.694 & 17.282 \\
\hline São Lourenço & 41.657 & 60.062 & 61.863 & 124 & 1.129 .007 & 188.168 \\
\hline São Sebastião do Paraíso & 64.980 & 93.689 & 96.500 & 193 & 1.761 .117 & 293.519 \\
\hline Três Pontas & 53.860 & 77.656 & 79.986 & 160 & 1.459 .738 & 243.290 \\
\hline Três Corações & 72.765 & 104.913 & 108.061 & 216 & 1.972 .109 & 328.685 \\
\hline Varginha & 123.081 & 177.460 & 182.783 & 366 & 3.335 .796 & 555.966 \\
\hline
\end{tabular}

Fonte: Autores.

A partir das áreas mínimas obtidas (Tabela 1) os municípios em foram agrupados em 4 extratos em função do tamanho necessário para os aterros, sendo o primeiro extrato até $50.000 \mathrm{~m}^{2}$, o segundo de 50.000 a $250.000 \mathrm{~m}^{2}$, o terceiro de 250.000 até $450.000 \mathrm{~m}^{2}$ e o quarto extrato de 450.000 até $700.000 \mathrm{~m}^{2}$. 
Na Figura 2 apresenta-se o primeiro extrato, com municípios de 5 das 12 microrregiões em estudo. A produção de RSU da maioria das famílias que moram em municípios de até 50.000 habitantes é atendida por algum sistema de coleta de lixo, com $12 \%$ desses municípios fazendo o descarte do RSU a céu aberto e $27 \%$ queimando ou enterrando o RSU produzido, sem nenhuma separação (Silva et al, 2018). Os munícipios de Fama, Ribeirão Vermelho e Ijaci enterram o RSU.

Figura 2 - Municípios do Sul e Sudoeste de Minas com demanda por aterro sanitário de até $50 \mathrm{mil} \mathrm{m}^{2}$ de área.

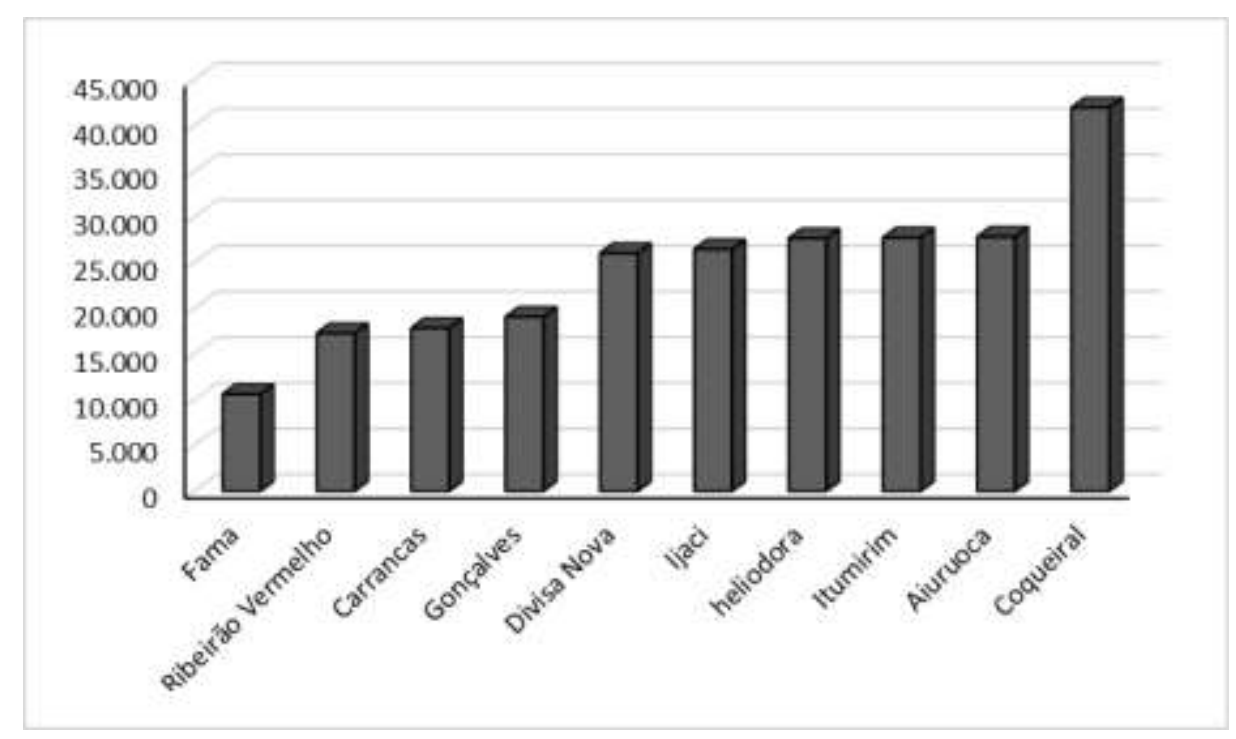

Fonte: Autores.

Os municípios do segundo extrato (50.000 a $250.000 \mathrm{~m}^{2}$ de aterro sanitário) são apresentados na Figura 3, onde é possível observar uma maior variação nos tamanhos. Os municípios de Perdões e Nepomuceno tem suas áreas de aterro em torno dos $100.000 \mathrm{~m}^{2}$, (Figura 3) e são municípios limítrofes podendo haver a possibilidade de um consórcio municipal para a implantação de um único aterro sanitário em localização que permita atender aos dois municípios. A criação de consórcios intermunicipais pode segundo Calderan et al. (2017), apresentar viabilidade social e econômica, trazendo assim benefícios aos municípios envolvidos.

Figura 3 - Municípios com demanda por aterros sanitários entre 50.000 e $250.000 \mathrm{~m}^{2}$ de área mínima.

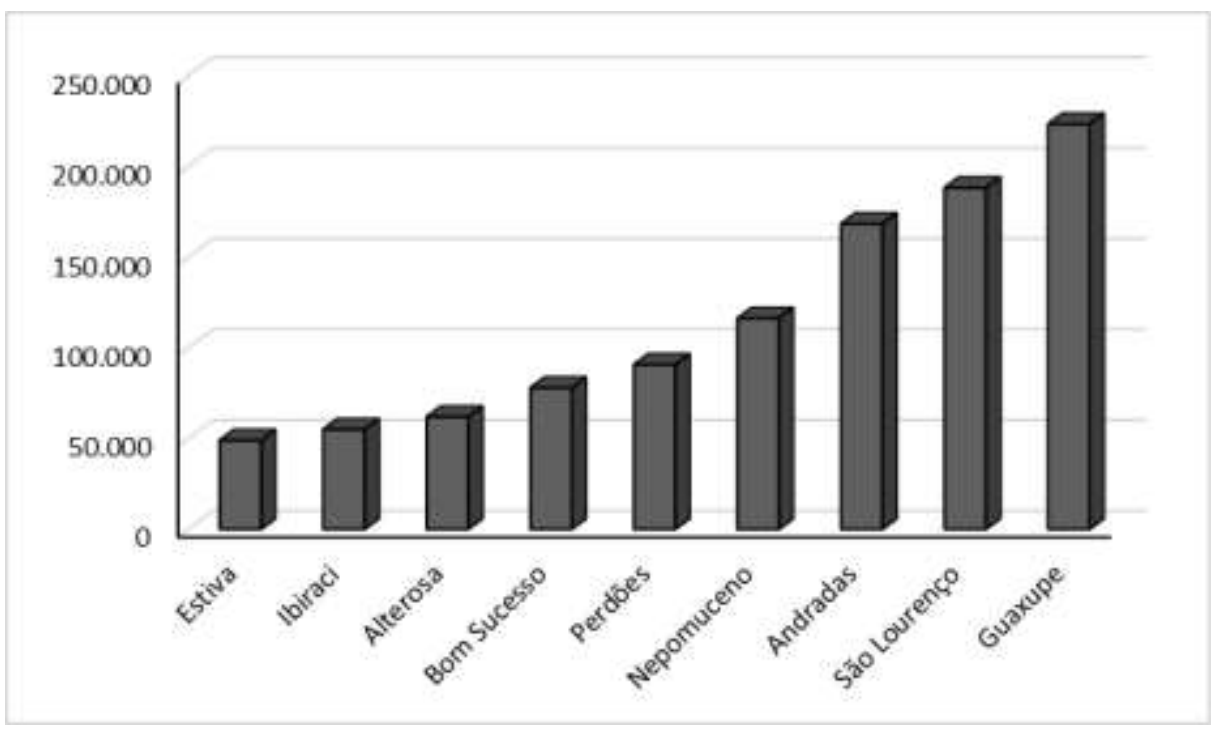

Fonte: Autores. 
Municípios com aterros considerados de médio porte estão indicados na Figura 4 Esses seis municípios têm população entre 50.000 e 100.000 habitantes, e ainda permitem a presença de um único aterro, embora bastante amplo em $\mathrm{m}^{2}$. Para aterros de médio porte já exige uma operação efetiva dos resíduos sendo necessária a coleta seletiva, para viabilizar os investimentos necessários ao longo de todo período de uso do aterro (Berticelli et al., 2020). Neste extrato encontram-se seis municípios, que tem população entre 50 mil e 230 mil habitantes.

Figura 4 - Municípios com demanda por aterros sanitários entre 250.000 e 450 mil m² de área.

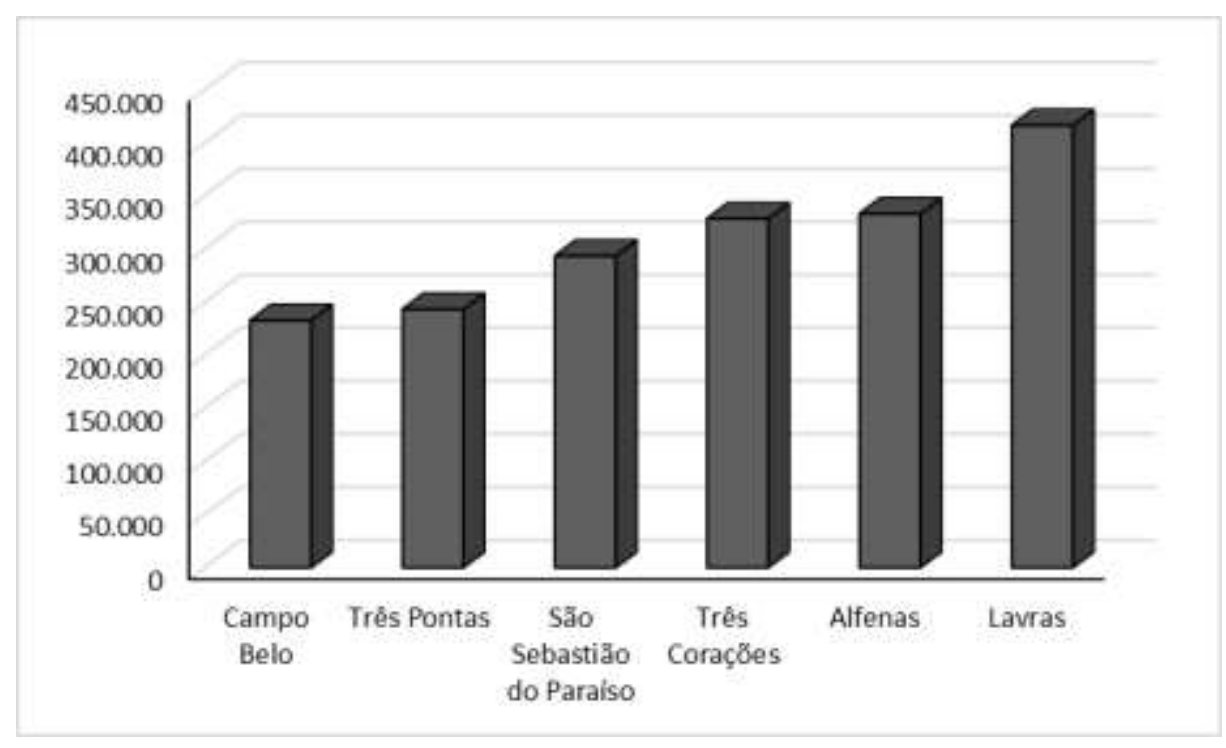

Fonte: Autores.

Os munícipios com demanda por aterros sanitários de grande porte estão apresentados na Figura 5 e são apenas quatro, dentro do grupo estudado, todos com mais de 100.000 habitantes no último censo (IBGE, 2010). Para aterros de grande porte outras demandas surgem e ações precisam ser realizadas para o bom aproveitamento do aterro, dentre estas ações tem-se coleta seletiva, queima de resíduos e produção de energia, implantação de fabricas de biogás, construção de dois aterros, dentre outros que precisam ser analisados a respeito de sua viabilidade econômica, (Rittl et al, 2020).

Figura 5 - Municípios com demanda por aterros sanitários com área de 450.000 a 700.000 mil m².

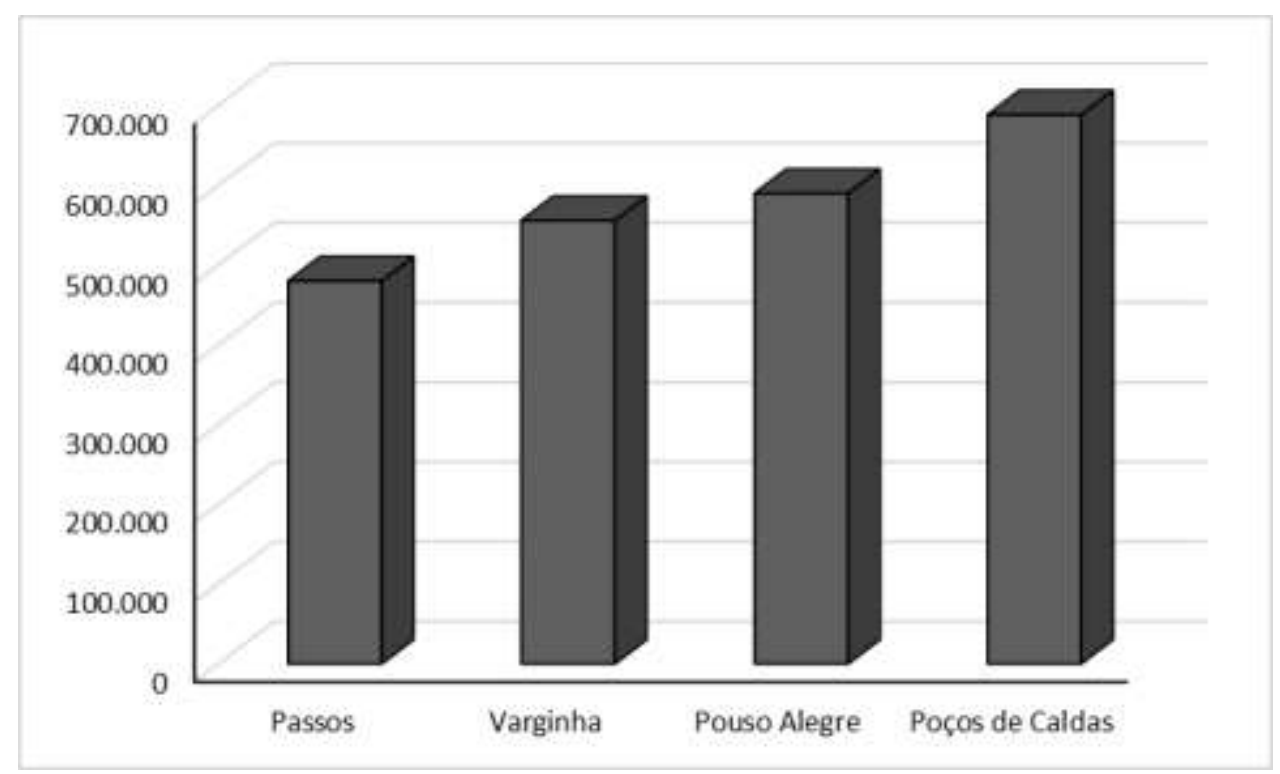

Fonte: Autores. 
Os resultados apresentados mostram a estimativa da área mínima do aterro sanitário de diferentes munícipios de duas regiões de Minas Gerais e podem servir como referência para municípios circunvizinhos com características populacionais semelhantes.

O desenvolvimento econômico do país e o aumento populacional geram maior consumo e consequentemente maior produção de RSU, conduzindo a incrementos na área destinada ao aterro, já que a produção per capita de RSU está diretamente ligada a esses fatores, sendo os países mais ricos os maiores produtores de RSU. Atualmente o brasileiro produz 1,03 $\mathrm{kg} \mathrm{dia}^{-1}$, nesse ritmo os aterros terão que ser cada vez maior para poder suportar todo esse crescimento de resíduos. Neste sentido, faz-se necessário cada vez mais estudos que mostrem a real situação dos municípios de modo que sirvam de alerta para os seus governantes e para a população, que visem a conscientização da população tanto para cobrar seus administradores quanto para diminuir a quantidade de RSU que é lançada no meio ambiente.

\section{Considerações Finais}

Cidades com mais de 100.000 habitantes precisam de aterros grandes ou mais aterros para melhorar a logística da coleta e transporte dos RSU;

A determinação da área mínima do aterro sanitário é muito importante para o processo de gestão dos resíduos, viabilidade econômica do mesmo, bem como para seleção do local adequado no município.

Em locais pequenos e próximos pode-se lançar mão dos consórcios intermunicipais para reduzir custos, favorecendo assim a implantação dos aterros.

Recomenda-se, em trabalhos futuros, avaliar além da proximidade dos municípios a viabilidade econômica de um eventual consórcio.

\section{Referências}

ABRELPE. (2017) Panorama dos Resíduos Sólidos no Brasil. Associação Brasileira de Empresas de Limpeza Pública e Resíduos Especiais, São Paulo. IBGE (2010) - Instituto Brasileiro De Geografia E Estatística. Censo 2010.

Associação Brasileira de Normas Técnicas-ABNT. (1984) Apresentação de projetos de aterros sanitários de resíduos sólidos urbanos - Procedimento. NBR8419/84. São Paulo, 13p.

Berticelli, R.; Decesaro, A.; Pandolfo, A. \& Pasquali, P. B. (2020) Contribuição da coleta seletiva para o desenvolvimento sustentável municipal. Revista em Agronegócios e Meio Ambiente,v. 13, n.2).

Calderan; T. B.; Mazzarino J. M. \& Turati, L. (2017) A potencialidade dos consórcios intermunicipais frente à política nacional de resíduos sólidos: Estudo de caso no COREDE - vale do taquari, RS, Brasil. Estudo \& Debate, v. 24, n. 3, p. 44-66.

FEMA-Fundação Estadual do Meio Ambiente. (2010) Reabilitação de áreas degradadas por resíduos sólidos urbanos. Fundação Estadual do Meio Ambiente; Fundação Israel Pinheiro. Belo Horizonte: FEMA, 36p.

Fulgencio, A. G. O (2009) Aterro Sanitário Intermunicipal de Quissamã-RJ: Uma reflexão sobre os instrumentos legais pertinentes à gestão de resíduos em pequenos municípios. Boletim do Observatório Ambiental Alberto Ribeiro Lamego, Campos dos Goytacazes/RJ, v.3, n.2, p. 91-108.

Jucá, J. F. T. (2003) Disposição final dos resíduos sólidos urbanos no Brasil. In: V CONGRESSO BRASILEIRO DE GEOTECNIA AMBIENTAL. Anais. Porto Alegre: REGEO, p. 443-470.

Lima, F. R. N. (2005) Localização de aterro sanitário utilizando lógica nebulosa. Dissertação de mestrado -Faculdade de Engenharia Civil- Universidade Federal do Rio de Janeiro.

Lourenço, R. W., da Cunha, D. C., Sales, J. C. A., de Medeiros, G. A., \& Otero, R. A. P. (2015). Metodologia para seleção de áreas aptas à instalação de aterros sanitários consorciados utilizando SIG. Ciência e Natura, 37(3), 122-140.

Norese, M. F. (2006) ELECTRE III as a support for participatory decision-making on the localization of waste-treatment plants. Land Use Policy, v. 23, p. 7685 .

Paula, G. S. D. (2017). Investigação das técnicas de impermeabilização de aterros utilizadas no estado do Paraná (Bachelor's thesis, Universidade Tecnológica Federal do Paraná). 
Research, Society and Development, v. 10, n. 11, e394101119801, 2021

(CC BY 4.0) | ISSN 2525-3409 | DOI: http://dx.doi.org/10.33448/rsd-v10i11.19801

Prado Filho, J. F. D. \& Sobreira, F. G. (2007). Desempenho operacional e ambiental de unidades de reciclagem e disposição final de resíduos sólidos domésticos financiadas pelo ICMS Ecológico de Minas Gerais. Engenharia Sanitária e Ambiental, 12(1), 52-61.

Rittl, L. G. F., Pincelli, I. P., Rutkowski, E. W., Moreira, G. A., De Medeiros, M. G., Cardoso, M. G., De Campos, T. M. P. ... \& De Castilhos Jr., A. B. (2020) Avaliação da implementação da rede internacional de cooperação acadêmica lixo zero (nizac) no Brasil. Revista Gestão \& Sustentabilidade Ambiental. 9(1)(esp), 269-87.

Russo, M. A. T. (2005): “Avaliação dos Processos de Transformação de Resíduos Sólidos Urbanos em Aterro Sanitário”. Tese de doutoramento. Universidade do Minho.

Santos, A. M. S. P. (2020). Política urbana no Brasil: a difícil regulação de uma urbanização periférica. Geo UERJ, (36), 47269.

Santos, D. L. (2019) Análise e dimensionamento de aterro sanitário para as cidades de Silvânia e Vianópolis. TCC, Curso de Engenharia Civil, UniEvangélica, Anápolis, GO, 83p.

Silva, X.J. \& Zaidan, T.R. (2004) Geoprocessamento e análise ambiental: aplicações. Rio de Janeiro: Bertrand Brasil. 368 p.

Silva, J. B., Ferreira Alves, L. S. \& Silva, M. M. N. (2018). Sustentabilidade, Políticas Públicas e Interdisciplinaridade no Semiárido. Ed. CCHLA.. 746 p.

Souza, H. A. (2002) Métodos e técnicas aplicados na avaliação ambiental do aterro da BR-040 da Prefeitura Municipal de Belo Horizonte - MG; REM: $R$. Esc. Minas, Ouro Preto, Pag.: 291-300. 